(C) 1984. The Genetical Society of Great Britain

\title{
GENE TRANSFER IN NICOTIANA RUSTICA BY MEANS OF IRRADIATED POLLEN. III. CYTOGENETICAL CONSEQUENCES IN THE SECOND GENERATION
}

\author{
C. P. WERNER AND M. A. CORNISH \\ Department of Genetics, University of Birmingham, PO Box 363, Birmingham B15 2TT, UK \\ Received 30.iii.84
}

\section{SUMMARY}

\begin{abstract}
$M_{1}$ plants derived from crosses using pollen irradiated with $20 \mathrm{Krad}$ of $\gamma$-rays were selfed and backcrossed reciprocally to $N$ rustica, $V_{27}$. A cytogenetical examination of these progenies revealed the persistence of considerable aneuploidy and structural aberrations. It proved possible to detect several aberrant chromosomes in the $\mathbf{M}_{1}$ parents and observe their transmission rates to the offspring. Analysis indicated some post-meiotic selection against these damaged, paternal chromosomes. The intensity of this selection, however, is insufficient to account for the maternal trend previously reported for the $\mathrm{M}_{2}$ generation in $N$. rustica. The preferred interpretation is that the mutational damage may lead to a loss in vigour during the $\mathrm{M}_{2}$ and equivalent generations.
\end{abstract}

\section{INTRODUCTION}

Following reports by Pandey (1975) and by Caligari, Ingram and Jinks (1981) attention has been drawn to the possible applications of pollen irradiation in plant breeding. Their work, with Nicotiana species, together with more recent studies using barley (Powell, Caligari and Hayter, 1983) and wheat (Snape, Parker, Simpson, Ainsworth, Payne and Law, 1983) suggests that the second $\left(\mathbf{M}_{2}\right)$ generation derived from irradiated pollen is largely maternal in phenotype but also includes some characters derived from the pollen parent. Pandey $(1975,1980,1983)$ has proposed three separate mechanisms to account for these results.

Cytogenetic studies of the $M_{1}$ generation in wheat (Snape et al., 1983) revealed many radiation induced mutations in the form of aneuploidy and multiple translocations. That such progenies were essentially hybrid in nature, modified by radiation damage, was confirmed by Werner, Dunkin, Cornish and Jones (1984) using intraspecific and interspecific crosses in Nicotiana. Contrary to the hypotheses proposed by Pandey, the maternal appearance of $\mathrm{M}_{2}$ offspring cannot be directly attributed to a largely maternal $M_{1}$ generation. An alternative hypothesis has been proposed by Snape et al. (loc. cit.) who suggest that damaged paternal chromosomes may be selectively lost during $\mathbf{M}_{1}$ meiosis or may lead to reduced viability of the resulting gametophytes or zygotes. In either event the radiation damage would lead to $\mathrm{M}_{2}$ progenies with an excess of the maternal genome. Werner et al. (loc. cit.) on the other hand, have suggested that at least some of the apparent maternal trends may be a result of the expression of radiation induced mutations inherited by the $\mathbf{M}_{2}$ progenies. It is, therefore, the nature of the second generation which is now of interest.

The cytogenetical study presented here was designed to determine the extent to which gamma-irradiated paternal chromosomes are transmitted 
to the progenies of $\mathrm{M}_{1}$ plants in $N$. rustica. The reciprocal backcrosses of $\mathbf{M}_{1}$ plants with the normal parent were included in this study in an attempt to detect selection which, if present, may differ in intensity between the two gametophytes. Further papers in this series will deal with the qualitative and quantitative genetics of this material.

\section{Materials AND Methods}

Two varieties of $N$. rustica $(2 n=48), V_{27}$ and $V_{12}$, (chosen to match those used by Caligari et al. (loc. cit.)), were crossed reciprocally using pollen treated with $20 \mathrm{Krad}$ of $\gamma$ radiation. Each of the $117 \mathrm{M}_{1}$ plants produced were selfed and backcrossed reciprocally to $\mathrm{V}_{27}$.

Twenty-two $M_{1}$ plants yielded sufficient seed (more than 60 seeds from a minimum of 3 pollinations) from each of the three crosses to permit their use in this cytological study. A random sample of ten of these $M_{1}$ plants was chosen for an examination of pollen mother cell meiosis. From these 10 plants four were randomly selected for the progeny studies, two derived from the irradiation of $V_{27}$ and two from the irradiation of $V_{12}$. Thirty progeny from each of the four $M_{1}$ plants were grown in the glasshouse; these consisted of ten backcross $\left(\mathrm{V}_{27} \times \mathrm{M}_{1}(\mathrm{BC})\right)$, ten reciprocal backcross $\left(M_{1} \times V_{27}(R B C)\right)$ and ten selfed $\left(M_{2}\right)$ progenies. Root tips from the parental $M_{1}$ plants and their progenies were used to investigate mitotic karyotypes using the methods described by Werner et al. (loc. cit.).

\section{RESUlts}

Of the ten $M_{1}$ plants subjected to meiotic analysis, nine showed evidence of at least one translocation at metaphase I. Six plants revealed overlapping translocations by the presence of complex configurations involving from six to ten chromosomes. In some cells as many as 22 chromosomes were involved in multivalent formations. Evidence of aneuploidy was also found, 2 plants being hyperploid with 49 chromosomes and 5 plants hypoploid ( 4 with 47 and 1 with 46 chromosomes) the remaining 3 plants had the euploid number of 48 . The presence of large deletions was unambiguously indicated by the occurrence of unequal bivalents. A maximum of 3 univalents per cell were observed during metaphase $I$ in nine of the plants. The tenth plant, however, exhibited from 5 to 23 univalents per cell, possibly as a consequence of disturbance of the meiotic control system.

The four $M_{1}$ plants used as parents in this study were all aneuploid (table 1), two being monosomic and two trisomic. In addition to these numerical aberrations it was possible to identify several structurally altered chromosomes from mitotic karyotypes. Such chromosomes must be paternal in origin and therefore serve as useful markers. It should be noted that some of the chromosomes which appeared normal at mitosis may have carried cryptic structural alterations such as equal and symmetric translocations and/or small deletions.

Since the $M_{1}$ parents were aneuploid for single chromosomes, one might expect half their gametes to be euploid with the remainder having one chromosome too few or too many. This hypothesis assumes regular and random meiotic segregation and the absence of gametophytic selection. Furthermore, if we make the same assumption for the damaged marker 
TABLE 1

The cytological composition of the 4 parental $M_{1}$ plants and their progenies. Each cell contains the number of plants with the karyotype indicated. (Key to abnormal chromosomes: a and $f=$ medium length acrocentrics, $b$ and $e=$ short metacentrics, $c=$ medium length telocentric, $d=$ short telocentric, $g$ and $h=$ short acrocentrics).

(i) $M_{1}$ 20830: mitotic karyotype : $49=48+a$

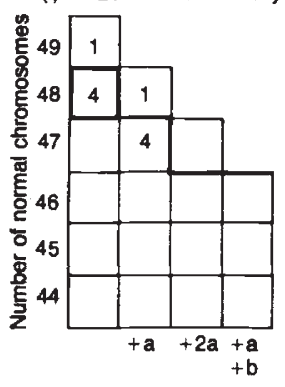

Abnormal chromosomes $\mathrm{BC}$

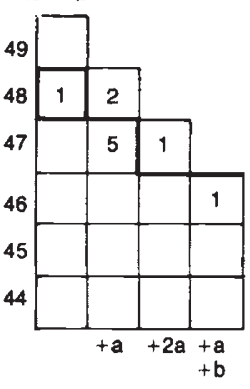

RBC

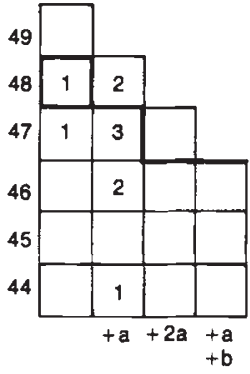

$M_{2}$

(ii) $M_{1}$ 20B42: mitotic karyotype : $47=44+2 c+d$

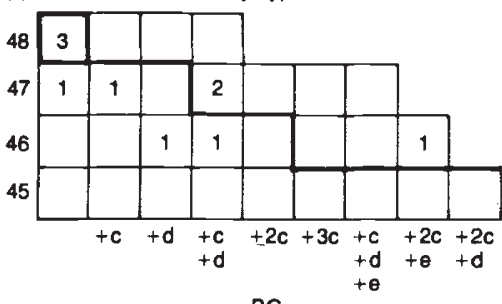

BC

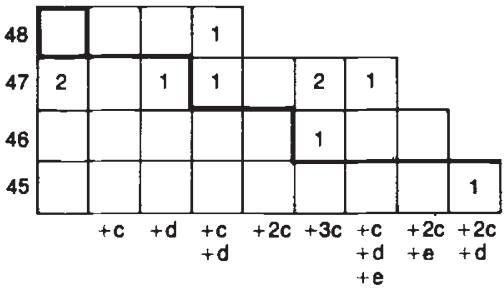

$M_{2}$

(iii) M, 20C60: mitotic karyotype : $47=45+f+g$
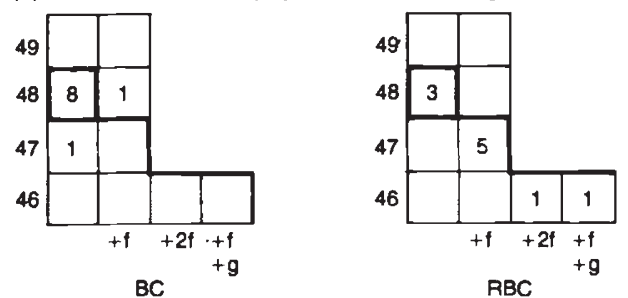

(iv) M1 20C79: mitotic karyotype : $49=48+h$
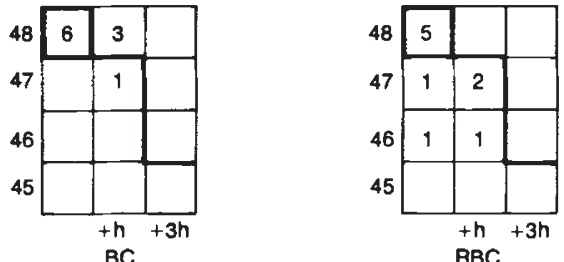

RBC

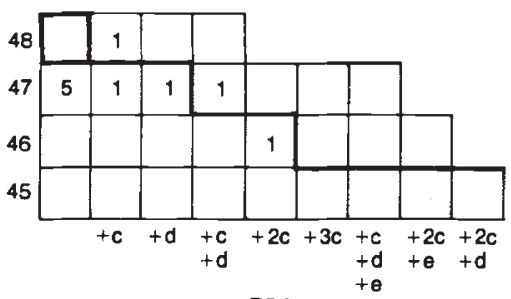

RBC
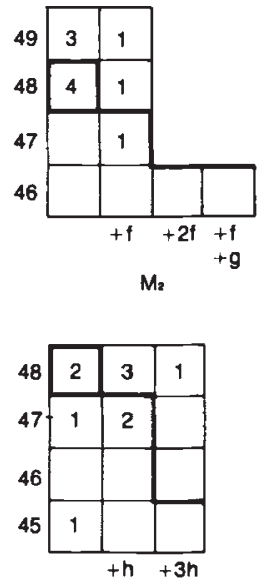

Mo 
chromosomes then half the gametes might be expected to carry a given marker chromosome and half its normal homologue.

The results from the mitotic survey of $B C, R B C$ and $M_{2}$ progenies derived from the four $M_{1}$ plants are presented in table 1 . A striking feature of these results is that 83 of the 120 individuals examined carried one or more numerical or structural aberrations. The pattern of transmission of this induced damage will be used to test the hypotheses stated above; the numerical aberrations will be considered first followed by the structural aberrations.

69 per cent of the plants in the backcross generations had the euploid number of chromosomes, significantly more than the 50 per cent expected $\left(\chi_{(1)}^{2}=11.25, p<0.001\right)$. The $M_{2}$ progenies show a similar trend, 37.5 per cent being euploid, compared with the 25 per cent expected. Some selection is clearly acting against aneuploidy. Several hypoploid progenies were recovered from the hyperploid parents and similarly hyperploid plants were derived from the hypoploid parents. These numerical aberrations may be considered to be secondary effects of the radiation, only occurring following meiosis in the $M_{1}$. Analysis of the progenies, from each $M_{1}$ plant separately, revealed no significant differences between the $B C$ and $R B C$ generations except for those from $M_{1}$ 20C79. In this case the $B C$ progenies included more hyperploid plants and the RBC more hypoploid plants (contingency chi-squared test, $\left.\chi_{(2)}^{2}=6.00, p=0.049\right)$. The intensity of selection may therefore, differ between the male and female gametophytes of this $M_{1}$ plant.

In the absence of zygotic selection the chromosomal constitution of the $\mathrm{M}_{2}$ progenies should reflect their gametic inputs, and these gametes should be predictable from the karyotypes of their respective reciprocal backcross families. A test of this hypothesis revealed, for the hypoploid $M_{1}$ plants, an excess of chromosomes in their $\mathrm{M}_{2}$ progenies relative to the backcrosses (contingency chi-squared test, $\chi_{(2)}^{2}=8.48, p=0.014$ ). One of the hyperploid $M_{1}$ plants (20B30), on the other hand, produced $M_{2}$ progenies with significantly fewer chromosomes than expected from the backcrosses (Fisher's exact test, $p=0.047$ ). These results may, therefore, be interpreted as evidence for zygotic selection which is acting more strongly in the $\mathbf{M}_{2}$ zygotes than in the backcross zygotes.

The transmission of the structurally altered marker chromosomes was variable (table 2): 2 were inherited normally, 1 showed preferential transmission and 3 were selected against. One of the latter chromosomes was subjected to significantly stronger selection in the male gametophyte than in the female. Differences were apparent even between chromosomes originating from the same $M_{1}$ plant. Clearly some aberrations are at more of a selective disadvantage than others and some appear to be less viable in one gametophyte than the other. The rates of transmission of these marker chromosomes to the $\mathrm{M}_{2}$ progenies are consistent with the observations from the backcrosses. They, therefore, provide no further evidence of zygotic selection. In addition to secondary numerical aberrations some of the derived progenies carried previously undetected structural aberrations, which may also be regarded as secondary consequences of the irradiation (e.g., table 1, chromosomes b and e).

Finally a significant reciprocal difference between the BC and RBC is apparent when all aberrations, both numerical and structural, are considered together. The frequency of $\mathrm{BC}$ plants with 48 normal chromosomes was 
TABLE 2

Summary and analysis of the transmission of the marker chromosomes

\begin{tabular}{|c|c|c|c|c|c|c|c|}
\hline Parent & $\begin{array}{c}\text { Marker } \\
\text { chromosome }\end{array}$ & Generation & \multicolumn{4}{|c|}{\begin{tabular}{lr}
\multicolumn{2}{c}{ No. of progenies } \\
without & with \\
marker & marker
\end{tabular}} & $\begin{array}{c}\text { Tests and } \\
\text { interpretation }\end{array}$ \\
\hline $20 \mathrm{~B} 30$ & $\begin{array}{l}\text { a } \\
\text { (medium length } \\
\text { acrocentric) }\end{array}$ & $\begin{array}{l}\text { BC } \\
\text { RBC }\end{array}$ & $\begin{array}{l}5 \\
1\end{array}$ & $\begin{array}{l}5 \\
5\end{array}$ & $\begin{array}{l}5 \\
9\end{array}$ & $\begin{array}{l}5 \\
5\end{array}$ & $\begin{array}{l}\text { No overall deviation } \\
\text { RBC shows an excess } \\
\text { of marker transmission } \\
\chi_{(1)}^{2}=6 \cdot 4, p=0.011\end{array}$ \\
\hline \multirow[t]{2}{*}{ 20B42 } & $\begin{array}{l}2 \mathrm{c} \\
\text { (medium length } \\
\text { telocentric) }\end{array}$ & $\begin{array}{l}\text { BC } \\
\text { RBC }\end{array}$ & $\begin{array}{l}5 \\
6\end{array}$ & $\begin{array}{l}2 \cdot 5 \\
2 \cdot 5\end{array}$ & $\begin{array}{l}5 \\
4\end{array}$ & $\begin{array}{l}7 \cdot 5 \\
7 \cdot 5\end{array}$ & $\begin{array}{l}\text { An overall deficiency } \\
\text { of the markers } \chi_{(1)}^{2}= \\
9.6, p=0.002\end{array}$ \\
\hline & $\begin{array}{l}\text { d } \\
\text { (short } \\
\text { telocentric) }\end{array}$ & $\begin{array}{l}\mathrm{BC} \\
\mathrm{RBC}\end{array}$ & $\begin{array}{l}6 \\
8\end{array}$ & $\begin{array}{l}5 \\
5\end{array}$ & $\begin{array}{l}4 \\
2\end{array}$ & $\begin{array}{l}5 \\
5\end{array}$ & $\begin{array}{l}\text { No significant depar- } \\
\text { tures from the expec- } \\
\text { ted frequency }\end{array}$ \\
\hline \multirow[t]{2}{*}{$20 \mathrm{C} 60$} & $\begin{array}{l}\mathrm{f} \\
\text { (medium length } \\
\text { acrocentric) }\end{array}$ & $\begin{array}{l}\text { BC } \\
\text { RBC }\end{array}$ & $\begin{array}{l}9 \\
3\end{array}$ & $\begin{array}{l}5 \\
5\end{array}$ & $\begin{array}{l}1 \\
7\end{array}$ & $\begin{array}{l}5 \\
5\end{array}$ & $\begin{array}{l}\text { BC shows a deficiency } \\
\text { of the marker } \chi_{(1)}^{2}= \\
6.4, p=0.011 . \text { There is } \\
\text { a difference between } \\
\text { the BC and RBC, } \\
\text { heterogeneity } \chi_{(1)}^{2}= \\
7 \cdot 2, p=0.007\end{array}$ \\
\hline & $\begin{array}{l}\text { g } \\
\text { (short } \\
\text { acrocentric) }\end{array}$ & $\begin{array}{l}\text { BC } \\
\text { RBC }\end{array}$ & $\begin{array}{r}10 \\
9\end{array}$ & $\begin{array}{l}5 \\
5\end{array}$ & $\begin{array}{l}0 \\
1\end{array}$ & $\begin{array}{l}5 \\
5\end{array}$ & $\begin{array}{l}\text { An overall deficiency } \\
\text { of the marker } \chi_{(1)}^{2}= \\
16.2, p<0.001\end{array}$ \\
\hline $20 C 79$ & $\begin{array}{l}\text { h } \\
\text { (short } \\
\text { acrocentric) }\end{array}$ & $\begin{array}{l}\text { BC } \\
\text { RBC }\end{array}$ & $\begin{array}{l}6 \\
7\end{array}$ & $\begin{array}{l}5 \\
5\end{array}$ & $\begin{array}{l}4 \\
3\end{array}$ & $\begin{array}{l}5 \\
5\end{array}$ & $\begin{array}{l}\text { No significant depar- } \\
\text { tures from the expec- } \\
\text { ted frequency }\end{array}$ \\
\hline
\end{tabular}

52.5 per cent whereas for the RBC this was only 22.5 per cent (contingency chi-squared test $\chi_{(1)}^{2}=6.45, p=0.011$ ). This confirms once again, the existence of stronger selection in the male gametophyte.

\section{Discussion}

These results have shown that many of the offspring carry one or more of the visible chromosome aberrations present in the $\mathbf{M}_{1}$. Furthermore, the extreme meiotic disturbance of the $M_{1}$ plants suggests that there may also be significant levels of cryptic structural rearrangements present in their progeny. This high incidence of chromosome aberrations is alone of considerable importance in the interpretation of $\mathbf{M}_{2}$ phenotypes. By design, similar material, treatment doses and techniques to those used by Caligari et al. (loc. cit.) were used to produce the two 20B $\mathrm{M}_{1}$ parents and hence their $\mathrm{M}_{2}$ progenies examined here. The $20 \mathrm{C} \mathrm{M}_{1}$ plants differed only with respect to the original direction of the cross. It can, therefore, be deduced that approximately 80 per cent of the $\mathrm{M}_{2}$ plants assessed by Caligari et al. under randomised field conditions carried one or more sizeable chromosome aberrations. This deduction strengthens the suggestion (Werner et al., 1984) 
that the apparent maternal trends observed in $N$. rustica may reflect, at least in part, a loss of vigour directly resulting from the deleterious effects of radiation induced damage.

Univalent loss during meiosis may be responsible, at least in part, for the euploid trend shown in the progenies of the hyperploid $\mathbf{M}_{1}$ parents. The disturbance of meiosis also generates secondary numerical and structural aberrations. Neither of these effects necessarily result in the transmission of more maternal material than expected and therefore they differ from the proposals of Snape et al. (loc. cit.) whereby the meiotic disturbances act selectively against damaged, paternal chromosomes.

Selection against the radiation induced aberrations does occur and differs in intensity from one aberration to another. The reciprocal differences between the $\mathrm{BC}$ and $\mathrm{RBC}$ progenies reflect stronger gametophytic selection in the pollen, an observation which accords with many studies of deletions or duplications such as those carried out in wheat by Sears (1954). The action of zygotic selection has also been confirmed by the discrepancy between the backcross and $\mathbf{M}_{2}$ progenies.

This reduced transmission of the aberrations from the $M_{1}$ to their progenies demonstrates, at least for these chromosomes, a trend towards a more maternal genome. Indeed, as suggested by Snape et al. (loc. cit.) this trend may account for the maternal phenotype of the $\mathbf{M}_{2}$ generation reported by themselves and by Caligari et al. (loc. cit.). However, the intensity of selection against the aberrations observed in this study is insufficient to account for the magnitude of the maternal trends reported by Caligari et al. If selection alone were responsible for the reduced final height observed in their $20 \mathrm{Krad} \mathrm{M}_{2}$ generation; then it would need to increase the average frequency of maternal alleles controlling this character to 82 per cent. (This calculation employs weighted least squares estimates of $m,[d]$ and $[h]$ to describe the generation means for this character. The average frequency of maternal alleles is increased by selection to $q$ which can be estimated from the equation for the $\mathrm{M}_{2}$ generation mean of $\left.m+(1-2 q)[d]+2(1-q) q[h]\right)$. For the structural aberrations reported here the average proportion of maternal chromosomes transmitted to the backcross and $\mathbf{M}_{2}$ generations was 67 per cent (taking the proportion of plants without the appropriate marker in the case of the backcrosses to be $q$ and for the $\mathbf{M}_{2}$ to be $q^{2}$ ). These aberrations are, however, the more severe forms of radiation damage and are likely to be selected against more strongly than the rest of the genome. A more probable explanation of the apparent maternal phenotype in $N$. rustica is the high frequency with which aneuploidy and deletions persist in the $\mathbf{M}_{2}$ generation. The relative importance of selection and mutational loss upon the phenotype will be considered in further papers in this series.

Acknowledgements. We thank Dr G. H. Jones for his advice and constructive criticism. We would also like to acknowledge the financial support received from the S.E.R.C. as a postgraduate research studentship (to C.P.W.) and from the A.F.R.C. (to M.A.C.).

\section{REFERENCES}

CALIGARI, P. D. S., INGRAM, N. R. AND JINKS, J. L. 1981. Gene transfer in Nicotiana rustica by means of irradiated pollen. I. Unselected progenies. Heredity, 47, 17-26. 
PANDEY, K. K. 1975. Transformation, incompatibility and plant improvement. Incompatibility Newsletter, 6, 91-121.

PANDEY, K. K. 1980. Further evidence for egg transformation in Nicotiana. Heredity, 45, 17-31.

PANDEY, K. K. 1983. Evidence for genetic transfer by the use of sublethally irradiated pollen in Zea mays and theory of occurrence by chromosome repair through somatic recombination and gene conversion. Molecular and General Genetics, 191, 358-365.

POWEll, W., CALIGARI, P. D. S. AND HAYTER, A. M. 1983. The use of pollen irradiation in plant breeding. Theoretical and Applied Genetics, 65, 73-76.

SEARS, E. R. 1954. The aneuploids of common wheat. Missouri Agricultural Experiment Station Research Bulletin, 572, 1-59.

SNAPE, J. W., PARKER, B. B., SIMPSON, E., AINSWORTH, C. C., PAYNE, P. I. AND LAW, C. N. 1983. The use of irradiated pollen for differential gene transfer in wheat (Triticum aestivum). Theoretical and Applied Genetics, 65, 103-111.

WERNER, C. P., DUNKIN, I. M., CORNISH, M. A. AND JONES, G. H. 1984. Gene transfer in Nicotiana rustica by means of irradiated pollen. II. Cytogenetical consequences. Heredity, 52, 113-119. 